\title{
Valuation of Quanto Caps and Floors in a Calibrated Multi-Curve Cross-Currency LIBOR Market Model
}

\author{
Charity Wamwea1, Philip Ngare², Martin Le Doux Mbele Bidima3 ${ }^{3}$, Susan Mwelu ${ }^{4}$ \\ ${ }^{1}$ Department of Mathematics, Pan African University Institute of Basic and Applied Sciences, Technology and Innovation, \\ Nairobi, Kenya \\ ${ }^{2}$ School of Mathematics, The University of Nairobi, Nairobi, Kenya \\ ${ }^{3}$ Department of Mathematics, University of Yaoundé I, Yaounde, Cameroon \\ ${ }^{4}$ Department of Statistics and Actuarial Sciences, Jomo Kenyatta University of Agriculture and Technology, Nairobi, Kenya \\ Email: wamweac@gmail.com,philipngare@gmail.com, mbelebidima@gmail.com,suemwelu@gmail.com
}

How to cite this paper: Wamwea, C., Ngare, P., Mbele Bidima, M.L.D. and Mwelu, S. (2019) Valuation of Quanto Caps and Floors in a Calibrated Multi-Curve Cross-Currency LIBOR Market Model. Journal of Mathematical Finance, 9, 698-725. https://doi.org/10.4236/jmf.2019.94036

Received: July 14, 2019

Accepted: October 27, 2019

Published: October 30, 2019

Copyright $\odot 2019$ by author(s) and Scientific Research Publishing Inc. This work is licensed under the Creative Commons Attribution International License (CC BY 4.0).

http://creativecommons.org/licenses/by/4.0/

\section{(c) (i) Open Access}

\begin{abstract}
Interest rate derivatives form part of the largest portion of traded financial instruments. Hence, it is important to have models that describe their dynamics accurately. This study aims at pricing quanto caps and floors using the multi-curve cross-currency LIBOR market model (MCCCLMM) dynamics. A Black Scholes MCCCLMM quanto caplet and floorlet formula is first derived. The MCCCLMM parameters are then calibrated to exactly match the USD and GBP cap market prices. The estimated model parameters are then used to price the quanto options in the Black MCCCLMM quanto caplet and floorlet formula. These prices are then compared to the quanto cap and floor prices estimated via Monte Carlo simulations so as to ascertain its pricing accuracy.
\end{abstract}

\section{Keywords}

Multiple Curves, Quanto, Cross Currency, LIBOR Market Model, Model Calibration, Cap or Floor Pricing

\section{Introduction}

Interest rate modeling has been a major interest amongst researchers. This is mostly because the interest rate markets have grown to dominate the financial world due to its vast number of traded financial products flooding the markets. According to [1], interest rate products form the largest portion of traded instruments in the financial markets. Initially, interest rates were modeled using 
the short rate models: [2] [3] [4] [5] [6] and many more. Later on, they were extended to model the instantaneous forward rates (see [7]) which were not directly observable. In the late nineties, a new class of models better known as the market models were introduced into the financial markets by authors such as [8] [9] [10]. These models were quickly accepted as they made use of market observable rates such as LIBORs and swap rates. Examples of such market models are the LIBOR market model (LMM) and the swap market model (SMM).

The term LIBOR stands for the London Interbank Offered rate. It is the benchmark rate at which major banks borrow from each other on a short term basis. This rate is monitored by ICE and is published daily for five different currencies and seven maturities. LIBOR is used widely in financial markets as the underlying in standard interbank products, commercial products, hybrid products and consumer related products. LIBOR equivalents also accepted globally are the European Interbank Offered Rate (EURIBOR), Tokyo Interbank Offered Rate (TIBOR), Shanghai Interbank Offered Rate (SHIBOR), and Mumbai Interbank Offered Rate (MIBOR).

Before 2007, the spread between the different LIBOR tenors was almost negligible. Hence, a single curve was sufficient for both discounting and in generating future cashflows. However, after the 2007 financial crisis, [11] noticed that this assumption could no longer hold as the spreads started becoming larger and larger to an extent that they could no longer be considered as negligible. Giving rise to the birth of multi-curve LIBOR market models (see Figure 1 and Figure 2 plotted using data collected from [12] and [13] respectively).

LIBOR USD DIFFERENT MATURITIES

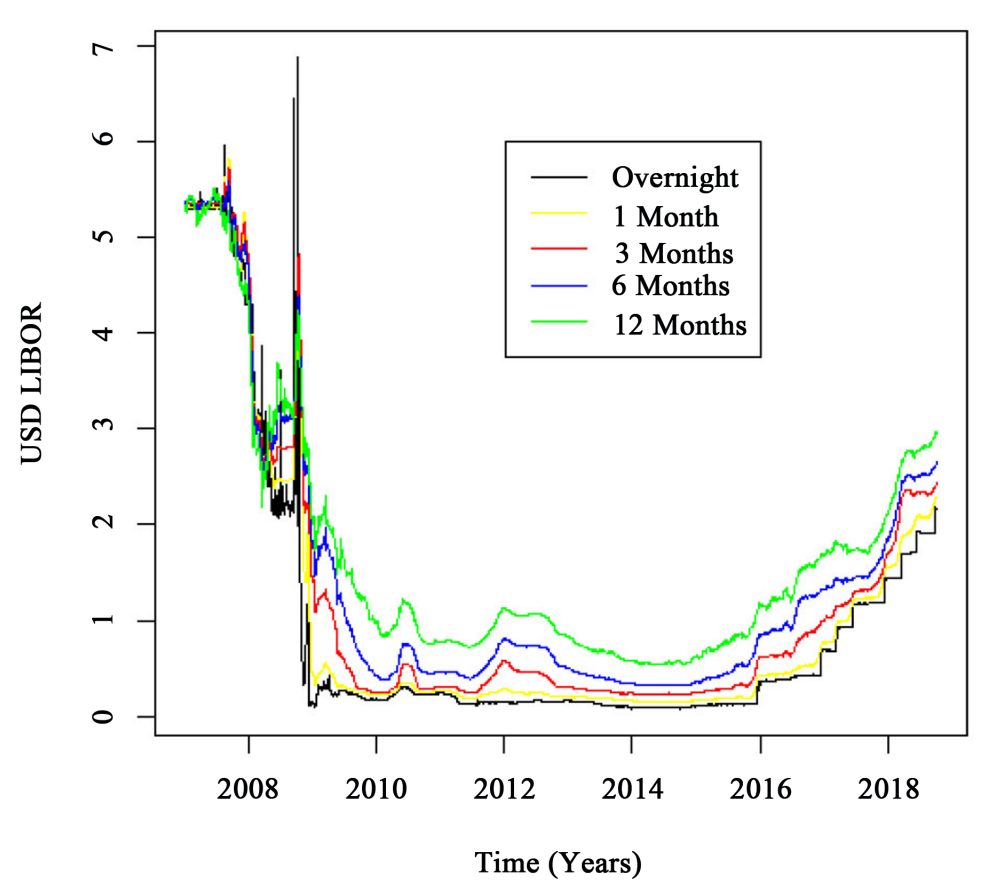

Figure 1. USD LIBOR. 
LIBOR GBP DIFFERENT MATURITIES

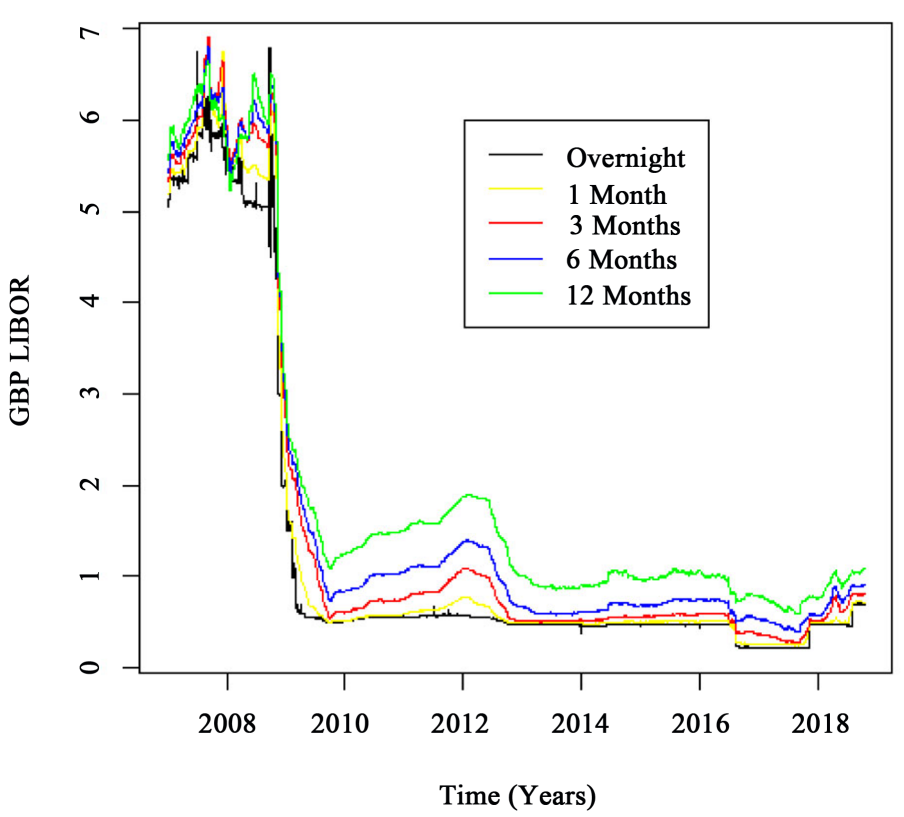

Figure 2. GBP LIBOR.

Under the multi-curve framework, one curve is used to generate future cashflows while the other one is used to discount the generated future cashflows. So far, many models have already been proposed in practice (see [11] [14]-[27] and so on).

Our main interest in this paper is in pricing quanto caps and floors using the multi-curve cross-currency LIBOR market model (MCCCLMM) dynamics introduced in [27]. The model parameters are first calibrated to exactly match the market observable cap prices. The estimated parameters from the calibration process are then used to essentially price quanto caps and floors in a Black MCCCLMM quanto caplet or floorlet formula derived in this paper. The quanto cap and floor prices are also estimated using Monte Carlo simulations and a comparison between the two models is done. The discretization scheme used to discretize the forward LIBORs is the Euler scheme.

However, the calibration problem, over the decades, has not been an easy one. It has seen researchers resort to both parametric and non-parametric techniques of calibrating the LIBOR market model (LMM). For instance, [28] developed a fast at the money (ATM) calibration of the LMM using Lagrange multipliers. He calibrated his model using ATM caps, swaptions and historical correlations. [29] came up with a numerical technique for calibrating financial models that essentially solves an inverse problem associated with some partial differential equations. [30] calibrated the LMM using cap and swaption price data collected on $16^{\text {th }}$ May 2010. They calibrated the cap volatilities using the Separable piecewise constant (SPC) parameterization technique and Linear-Exponential (L-E) formulation both under the general piecewise constant assumption. They estimated 
their model correlations using swaptions. [31] explains the different types of assumptions that can be made on the general piecewise constant technique for cap volatilities. [32] explains the concept behind the general piecewise constant. $\mathrm{He}$ goes further ahead to explain that the main problem in calibrating the LMM is in finding a volatility function that accurately reproduces a sample of market derivative prices e.g. cap and swaption prices.

In this paper, the instantaneous correlations are estimated from historical rates. The general piecewise constant assumption was assumed on the cap volatilities. The foreign exchange rate volatility was also estimated from historical data.

\section{Materials and Methods}

In this section, the relevant tools, models, methods and tests used are presented.

\subsection{Data}

The datasets considered in this study were: Historical overnight and 6 month USD and GBP LIBORs ranging from 2/1/2008 to 2/1/2018 collected from [12] and [13] respectively. The GBP/USD foreign exchange rate data ranging from $2 / 1 / 2008$ to $2 / 1 / 2018$ collected from [33]. UK gilts and US Treasury rates collected from [34] and [35] respectively on 2/1/2018. Finally, the GBP and USD cap prices collected from [36].

\subsection{Data Analysis Tool}

$\mathrm{R}$ open software version 3.1.2 was used in simulating and analysing all the data in this study. Useful packages considered were "MASS", "sde", and "lmtest".

\subsection{Model Notations}

Let $X(t)$ be the spot foreign exchange rate at time t quoted as the ratio of units of United States Dollar (USD) to one unit of Pound Sterling (GBP). $d$ be the US (domestic) economy and $f$ be the UK (foreign) economy. $D$ and $L$ denote the risk-free and risky curves respectively. $r_{d}^{D}$ and $r_{f}^{D}$ be the risk-free short rates of interest associated with the US and UK economies respectively. In addition to this, $P_{d}^{D}(t, T)$ and $P_{f}^{D}(t, T)$ denote the risk-free zero coupon bonds in the domestic and foreign economies respectively. $L_{d}^{D}(t, T)$ and $L_{f}^{D}(t, T)$ denote the simply compounded overnight LIBORs associated with US and UK markets respectively. Last but not least, $L_{d}(t, T)$ and $L_{f}(t, T)$ denote the 6 month LIBOR associated with the US and UK markets.

\subsection{The Multi-Curve Cross-Currency LIBOR Market Model (MCCCLMM)}

The stochastic differential equations associated with the MCCCLMM dynamics that were considered in this study under the spot domestic risk neutral measure were given by: 


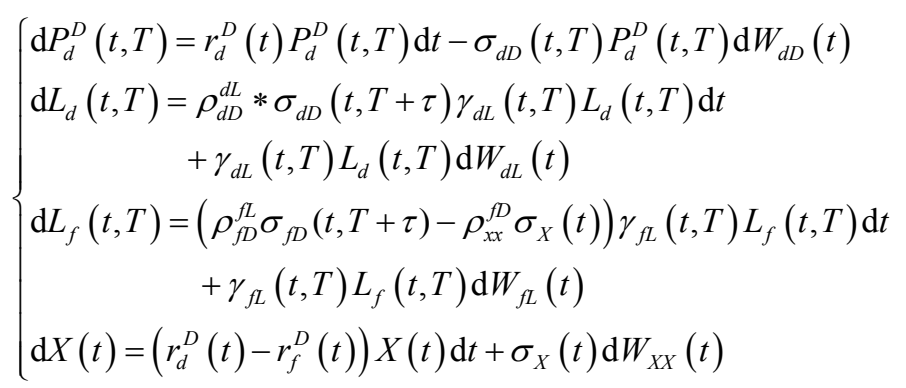

where

$$
\begin{gathered}
\sigma_{k D}(t, T)=\sum_{j=1}^{\left\lfloor\tau^{-1}(T-t)\right\rfloor} \frac{\tau L_{k}^{D}(t, T-j \tau)}{1+\tau L_{k}^{D}(t, T-j \tau)} \gamma_{k D}(t, T-j \tau) \\
\sigma_{k L}(t, T)=\sum_{j=1}^{\left\lfloor\tau^{-1}(T-t)\right\rfloor} \frac{\tau L_{k}(t, T-j \tau)}{1+\tau L_{k}(t, T-j \tau)} \gamma_{k L}(t, T-j \tau)
\end{gathered}
$$

$\left\lfloor\tau^{-1}(T-t)\right\rfloor$ denotes the greatest integer that is less than $\tau^{-1}(T-t)$. And

$$
W=\left[\begin{array}{c}
W_{d D} \\
W_{d L} \\
W_{f D} \\
W_{f L} \\
W_{X X}
\end{array}\right]
$$

is a correlated Wiener process with a correlation matrix given by:

$$
\Sigma=\left(\begin{array}{ccccc}
1 & \rho_{d D}^{d L} & \rho_{d D}^{f D} & \rho_{d D}^{f L} & \rho_{x x}^{d D} \\
\rho_{d D}^{d L} & 1 & \rho_{d L}^{f D} & \rho_{d L}^{f L} & \rho_{x x}^{d L} \\
\rho_{d D}^{f D} & \rho_{d L}^{f D} & 1 & \rho_{f D}^{f L} & \rho_{x x}^{f D} \\
\rho_{d D}^{f L} & \rho_{d L}^{f L} & \rho_{f D}^{f L} & 1 & \rho_{x x}^{f L} \\
\rho_{x x}^{d D} & \rho_{x x}^{d L} & \rho_{x x}^{f D} & \rho_{x x}^{f L} & 1
\end{array}\right)
$$

where it is assumed that the Wiener processes are governed by constant correlation factors such that

$$
\rho_{i}^{j}= \begin{cases}\rho_{j}^{i} & \text { if } j \neq k ; \quad j, k \in\{d D, d L, f D, f L, x x\},\left|\rho_{j}^{k}\right| \leq 1 \\ 1 & \text { if } j=k\end{cases}
$$

\subsection{Calibration of MCCCLMM Parameters to Market Data}

Calibration is the process of estimating the model parameters such that they match the market prices.

\subsubsection{Estimation of MCCCLMM Correlations}

The constant correlations $\rho_{i}^{j}$ can be estimated using the Pearson's correlation formula given by:

$$
r=\frac{\sum_{i=1}^{n}\left(X_{i}-\bar{X}\right)\left(Y_{i}-\bar{Y}\right)}{\sqrt{\sum_{i=1}^{n}\left(X_{i}-\bar{X}\right)^{2} \sum_{i=1}^{n}\left(Y_{i}-\bar{Y}\right)^{2}}}
$$




\subsubsection{Estimation of Foreign Exchange Rate Volatility from Historical Rates}

Given that the SDE of the foreign exchange rate is given by:

$$
\frac{\mathrm{d} X_{t}}{X_{t}}=\mu_{X} \mathrm{~d} t+\sigma_{X} \mathrm{~d} W_{x x}(t)
$$

then the SDE can be discretised as follows:

$$
\begin{aligned}
\frac{\mathrm{d} X_{t}}{X_{t}} & =\mathrm{d} \ln X_{t} \\
& =\ln \left(X_{t}\right)-\ln \left(X_{t-1}\right) \\
& =\ln \left(\frac{X_{t}}{X_{t-1}}\right) \\
& =\mu_{X} \Delta t+\sigma_{X} \Delta W_{x x}(t)
\end{aligned}
$$

and according to [37], for one to estimate the volatility parameter from historical rates, the following steps should be considered:

1) Calculate the logarithmic returns as follows:

$$
l_{i}=\ln \left(\frac{X_{i}}{X_{i-1}}\right) ; i \in\{1,2, \cdots, n\}
$$

2) Calculate the mean of the logarithmic returns as follows:

$$
\bar{l}=\sum_{i=1}^{n} l_{i}
$$

3) Calculate the unbiased standard deviation of the logarithmic returns as follows:

$$
s_{l}=\frac{1}{n-1} \sum_{i=1}^{n}\left(l_{i}-\bar{l}\right)^{2}
$$

and now $\sigma_{X}$ can be estimated as

$$
\hat{\sigma}_{X}=\frac{s_{l}}{\Delta t}
$$

\subsubsection{Parameterization of the Forward LIBOR Volatility}

In this paper, the constant maturity-dependent volatility assumption under the general piecewise constant technique is considered. [31] explains in detail the possible assumptions that can be considered under this technique. It is assumed that

$$
\gamma_{i}(t)=S_{i} ; 0<t \leq T_{i-1}
$$

Calibrating the model to caplet amounts is equivalent to choosing deterministic LIBOR volatilities of forward rates $\gamma_{1}, \gamma_{2}, \cdots, \gamma_{m}$ such that:

$$
v_{T_{i} \text {-cap }}^{2}=\frac{1}{T_{i-1}} \int_{0}^{T_{i-1}} \gamma_{i}^{2}(t) \mathrm{d} t ; i=\{1,2, \cdots, m\}
$$

The $\gamma$ values are as summarised in Table 1 .

Under this assumption, 
Table 1. Constant maturity volatility assumption.

\begin{tabular}{ccccc}
\hline Forward LIBOR & $t \in\left(0, T_{0}\right]$ & $\left(T_{0}, T_{1}\right]$ & $\cdots$ & $\left(T_{m-2}, T_{m-1}\right]$ \\
\hline$L_{1}(t)$ & $S_{1}$ & dead & $\cdots$ & dead \\
$L_{2}(t)$ & $S_{2}$ & $S_{2}$ & $\cdots$ & dead \\
$\vdots$ & $\vdots$ & $\vdots$ & $\vdots$ & $\vdots$ \\
$L_{m}(t)$ & $S_{m}$ & $S_{m}$ & $\cdots$ & $S_{m}$ \\
\hline & & & & \\
& $T_{i-1} v_{T_{i}-\text { cap }}^{2}=T_{i-1} S_{i}^{2}$ & for $i \in\{1,2, \cdots, m\}$ & \\
& $v_{T_{i}-\text { cap }}^{2}=S_{i}^{2}$ & & &
\end{tabular}

The advantage of using this assumption is that the $S$ parameters fit the market cap volatilities.

\subsubsection{Calibration via the Black MCCCLMM Formula}

It was assumed that in the U.S economy, the USD LIBOR is a domestic rate. In the same way, in the British economy, the GBP LIBOR is also a domestic rate. Hence under the domestic risk neutral measure, the MCCCLMM dynamics of the risky USD or GBP LIBOR in either domestic economies is given by:

$$
\frac{\mathrm{d} L_{k}(t, T)}{L_{k}(t, T)}=\rho_{k D}^{k L} * \sigma_{k D} * \gamma_{k L} * \mathrm{~d} t+\gamma_{k L} * \mathrm{~d} W_{k L}(t) ; k \in\{d, f\}
$$

The Black-like formula for calculating USD or GBP caplets or floorlets in the respective domestic currencies is given by:

$$
C_{k}(t)=\omega \tau P_{k}^{D}(t, T)\left(L_{k}(t, T) * \mathrm{e}^{\rho_{k D}^{k L} * \sigma_{k D} * \gamma_{k L}(T-t)} * \Phi\left(\omega d_{11}\right)-K_{k} * \Phi\left(\omega d_{21}\right)\right)
$$

where

$$
\begin{aligned}
& \omega= \begin{cases}+1 \quad \text { if it is a caplet contract } \\
-1 \quad \text { if it is a floorlet contract }\end{cases} \\
& d_{11}=\frac{\ln \left(\frac{L_{k}(T, T)}{K_{k}}\right)+\left(\rho_{k D}^{k L} * \sigma_{k D} * \gamma_{k L}+0.5 \gamma_{k L}^{2}\right)(T-t)}{\gamma_{k L} * \sqrt{T-t}} \\
& d_{21}=d_{11}-\gamma_{k L} * \sqrt{T-t}
\end{aligned}
$$

The MCCCLMM parameters fitted in the Black-like formula described in Equation (16), were minimized to exactly match the cap prices collected from [36].

\subsection{Yield Curve Bootstrapping}

Bootstrapping in finance is the process of constructing a zero coupon yield curve from a set of coupon bearing instruments by filling in the missing yields. In this research, the Nelson Siegel Svenssons (NSS) method is used. The NSS method given by 


$$
y(t)=\beta_{0}+\beta_{1}\left(\frac{1-\mathrm{e}^{\frac{-t}{\lambda_{1}}}}{\frac{t}{\lambda_{1}}}\right)+\beta_{2}\left(\frac{1-\mathrm{e}^{\frac{-t}{\lambda_{1}}}}{\frac{t}{\lambda_{1}}}-\mathrm{e}^{\frac{-t}{\lambda_{1}}}\right)+\beta_{3}\left(\frac{1-\mathrm{e}^{\frac{-t}{\lambda_{2}}}}{\frac{t}{\lambda_{2}}}-\mathrm{e}^{\frac{-t}{\lambda_{2}}}\right)
$$

is used to bootstrap the yield curve from the USD treasury and UK gilt rates. The NSS model parameters $\beta_{0}, \beta_{1}, \beta_{2}, \beta_{3}, \lambda_{1}$ and $\lambda_{2}$ are estimated by minimizing the sum of squared errors (SSE):

$$
\min \sum\left(y^{A}-y\right)^{2}
$$

where $y^{A}$ are the actual market rates and $y$ are the rates estimated via the NSS method. The zero coupon bond prices are then estimated using the formula:

$$
Z(t)=(1+y(t))^{-t}
$$

\subsection{Mean Error Analysis}

The option prices estimated using the Black's formula were compared with the mean Monte Carlo simulated option prices using the mean absolute percentage error (MAPE) given by:

$$
\text { MAPE }=\frac{1}{n} \sum_{i=1}^{n} \frac{\left|B P_{i}-M P_{i}\right|}{B P_{i}} * 100 \%
$$

where $B P_{i}$ is Black price and $M P_{i}$ is the Monte Carlo price.

According to [38], if MAPE $\leq 10 \%$, then the model is considered to be highly accurate. If $10 \%<\mathrm{MAPE} \leq 20 \%$, then the model is considered to be a good model. If $20 \%<\mathrm{MAPE} \leq 50 \%$, then the model is considered to be reasonable, and if MAPE $>50 \%$ then the model is taken to be inaccurate.

\subsection{MCCCLMM Simulation}

In this section, a brief introduction of the discretization scheme used in our simulations is done, how the correlated Wiener processes were generated, and finally how the cap and floor prices were simulated is given.

\subsubsection{Discretization Scheme}

The Euler discretization scheme [39] was used to discretize our calibrated model dynamics so as to enable us to simulate the risky forward LIBORs in discrete time.

Consider an Itô process $\left\{X_{t}\right\}_{0 \leq t \leq T}$ with a stochastic differential Equation (SDE) given by:

$$
\mathrm{d} X_{t}=\mu\left(t, X_{t}\right) \mathrm{d} t+\sigma\left(t, X_{t}\right) \mathrm{d} W_{t}
$$

and an initial deterministic value of $X_{0}=x_{0}$. Then the Euler approximation of $X_{t}$ for the interval $t \in[0, T]$; is a process $Y$ such that $0=t_{0}<t_{1}<\cdots<t_{N}=T$ satisfies the iterative scheme:

$$
Y_{i+1}=Y_{i}+\mu\left(t_{i}, Y_{i}\right)\left(t_{i+1}-t_{i}\right)+\sigma\left(t_{i}, Y_{i}\right)\left(W_{i+1}-W_{i}\right) ; i=0,1,2, \cdots, N-1
$$

where $Y_{0}=X_{0}$. 


\subsubsection{Generation of Correlated Wiener Processes}

According to [40], the correlated Wiener process, $W$ can be simulated by applying Cholesky decomposition as follows:

$$
W=A Z
$$

In our case, this is given by:

$$
\left(\begin{array}{l}
\mathrm{d} W_{d D} \\
\mathrm{~d} W_{d L} \\
\mathrm{~d} W_{f D} \\
\mathrm{~d} W_{f L} \\
\mathrm{~d} W_{x x}
\end{array}\right)=\left(\begin{array}{ccccc}
1 & 0 & 0 & 0 & 0 \\
a & b & 0 & 0 & 0 \\
c & d & e & 0 & 0 \\
f & g & h & i & 0 \\
j & k & l & m & n
\end{array}\right)\left(\begin{array}{l}
\mathrm{d} Z_{1} \\
\mathrm{~d} Z_{2} \\
\mathrm{~d} Z_{3} \\
\mathrm{~d} Z_{4} \\
\mathrm{~d} Z_{5}
\end{array}\right)
$$

where:

$Z_{i} ; i \in\{1,2,3,4,5\}$ are independent standard normal variables.

$$
\begin{gathered}
a=\rho_{d D}^{d L} ; \quad b=\sqrt{1-a^{2}} ; \quad c=\rho_{d D}^{f D} \\
d=\frac{\rho_{d D}^{f D}-a c}{b} ; \quad e=\sqrt{1-c^{2}-d^{2}} ; \quad f=\frac{\rho_{d D}^{f L}-a c}{b} \\
g=\frac{\rho_{d L}^{f L}-a f}{b} ; \quad h=\frac{\rho_{f D}^{f L}-c f-d g}{e} ; \quad i=\sqrt{1-f^{2}-g^{2}-h^{2}} \\
j=\rho_{x x}^{d D} ; \quad k=\frac{\rho_{x x}^{d L}-a j}{b} ; \quad l=\frac{\rho_{x x}^{f D}-c j-d k}{e} \\
m=\frac{\rho_{x x}^{f L}-f j-g k-h l}{i} ; \quad n=\sqrt{1-j^{2}-k^{2}-l^{2}-m^{2}}
\end{gathered}
$$

Remark: See proof in [27].

\subsubsection{Simulation of USD Cap and Floor Prices}

To price USD interest rate options, it was assumed that the USD LIBOR is a domestic rate in the US. The dynamics used to simulate the USD Forward risky LIBOR in the US economy were given by:

$$
\left\{\begin{array}{l}
a_{1}=\rho_{d D}^{d L} \\
\mathrm{~d} W_{d L}=a_{1} * Z_{1}+Z_{2} \sqrt{1-a_{1}^{2}} \\
\ln L_{d}\left(T_{i}\right)=\ln L_{d}\left(T_{i-1}\right)+\rho_{d D}^{d L} * \sigma_{d D} * \gamma_{d L} * \Delta t+\gamma_{d L} * \sqrt{\Delta t} * \mathrm{~d} W_{d L}
\end{array}\right.
$$

The formula expressed in Equation (28) was used to simulate USD cap or floor prices at time $t$.

$$
U(t)=\Delta t * N_{d} * \sum_{i=1}^{n} P_{d}^{D}\left(t, T_{i}\right) * \max \left(\omega\left(L_{d}\left(T_{i}\right)-K_{d}\right), 0\right)
$$

where $N_{d}$ is the notional principal of the USD interest rate option.

\subsubsection{Simulation of GBP Cap and Floor Prices.}

To price GBP interest rate options, it was first assumed that the GBP LIBOR is a domestic rate in the U.K. The dynamics used to simulate the GBP Forward risky LIBOR in the U.K economy were given by: 


$$
\left\{\begin{array}{l}
a_{2}=\rho_{f D}^{f L} \\
\mathrm{~d} W_{f L}=a_{2} * Z_{1}+Z_{2} \sqrt{1-a_{2}^{2}} \\
\ln L_{f}\left(T_{i}\right)=\ln L_{f}\left(T_{i-1}\right)+\rho_{f D}^{f L} * \sigma_{f D} * \gamma_{f L} * \Delta t+\gamma_{f L} * \sqrt{\Delta t} * \mathrm{~d} W_{f L}
\end{array}\right.
$$

The formula expressed in Equation (30) was used to simulate GBP cap or floor prices at time, $t$.

$$
G(t)=\Delta t * N_{f} * \sum_{i=1}^{n} P_{f}^{D}\left(t, T_{i}\right) * \max \left(\omega\left(L_{f}\left(T_{i}\right)-K_{f}\right), 0\right)
$$

where $N_{f}$ is the notional principal of the GBP interest rate option.

\subsubsection{Simulation of Quanto Cap and Floor Prices}

To price GBP options in the US that remits payments in GBP, it is first assumed that the GBP LIBOR is a foreign rate in the US. The dynamics used to simulate the foreign Forward risky LIBORs under the spot domestic risk neutral measure, $\mathbb{Q}^{D}$, in the domestic economy was given by;

$$
\left\{\begin{array}{l}
\mathrm{d} W_{f L}=f * Z_{1}+g * Z_{2}+h * Z_{3}+i * Z_{4} \\
\ln L_{f}\left(T_{i}\right)=\ln L_{f}\left(T_{i-1}\right)+\left(\rho_{f D}^{f L} * \sigma_{f D}-\rho_{x x}^{f L} * \sigma_{x}\right) * \gamma_{f L} * \Delta t+\gamma_{f L} * \sqrt{\Delta t} * \mathrm{~d} W_{f L}
\end{array}\right.
$$

The formula expressed in Equation (32) was used to simulate Quanto cap or floor prices at time, $t$.

$$
Q(t)=\Delta t * X^{0} * N_{f} * \sum_{i=1}^{n} P_{d}^{D}\left(t, T_{i}\right) * \max \left(\omega\left(L_{f}\left(T_{i}\right)-K_{f}\right), 0\right)
$$

where $N_{f}$ is the notional principal of the GBP interest rate option.

\subsection{Black MCCCLMM Quanto Caplet or Floorlet Formula}

A quanto is an interest rate derivative that allows the holder to receive payment in a currency different from that of the underlying. A caplet is a call optional derivative that offers payment to the holder whenever the interest rate exceeds the cap price at maturity and a cap is a series of caplets. A floorlet is the opposite of a caplet. It is a put optional derivative that offers payment to the holder whenever the put rate exceeds the interest rate at maturity and in the same way, a floor is a series of floorlets. In this section, it was assumed that there exists a domestic investor interested in hedging against foreign interest rate risk. It was also assumed that the investor prefers using their domestic currency in trading as opposed to using the foreign currency. Hence, the underlying in the quanto options are considered to be struck in foreign currency and payments converted into domestic currency using a fixed exchange rate.

Theorem 1 (Black Scholes MCCCLMM Quanto-Caplet/Floorlet Formula). Assuming that the dynamics of the multi-curve cross currency LIBOR market model under the spot domestic martingale measure $\mathbb{Q}^{D}$ is as defined in Equation (1) and further assuming the underlying $L_{f}($.$) , is struck in foreign cur-$ rency. Then the payoff at maturity of a quanto caplet or floorlet expressed in 
domestic currency is given by:

$$
\tau N_{f} X^{0}\left(\omega *\left(L_{f}(T, T)-K_{f}\right)\right)^{+}
$$

and the arbitrage free price of the quanto caplet or floorlet at time $t \leq T$ is given by.

$$
\begin{aligned}
& Q\left(t, T, K_{f}, X^{0}, N_{f}\right) \\
& =\tau \omega N_{f} X^{0} P_{d}^{D}(t, T)\left[L_{f}(t, T) \mathrm{e}^{\left(\rho_{f D}^{f L} * \sigma_{d D}-\rho_{x x}^{f L} * \sigma_{X}\right) * \gamma_{f L} *(T-t)} \Phi\left(\omega d_{1}\right)-K_{f} * \Phi\left(\omega d_{2}\right)\right]
\end{aligned}
$$

where

$$
\begin{gathered}
\omega= \begin{cases}+1 & \text { if it is a caplet contract } \\
-1 & \text { if it is a floorlet contract }\end{cases} \\
d_{1}=\frac{\ln \left(\frac{L_{f}(t, T)}{K_{f}}\right)+\left(\left(\rho_{f D}^{f L} * \sigma_{d D}-\rho_{x x}^{f L} * \sigma_{X}\right) * \gamma_{f L}+\frac{1}{2} * \gamma_{f L}^{2}\right)(T-t)}{\gamma_{f L} * \sqrt{T-t}} \\
d_{2}=d_{1}-\gamma_{f L} * \sqrt{T-t}
\end{gathered}
$$

$\Phi($.$) is the cdf of a standard normal distribution.$

Remark See derivation of Black Scholes MCCCLMM Quanto Caplet formula in Appendix.

\section{Numerical Results}

The MCCCLMM model parameters were calibrated to real world data using ATM cap prices and historical rates. The parameters were then used to price quanto caps and floors under the MCCCLMM.

\subsection{Data Description}

Six months spaced ten year historical data was used in this study to estimate the model correlations and foreign exchange rate volatility. The data was taken for the period beginning from 2nd January 2008 to 2 nd January 2018. The data consisted of the Overnight and 6 month GBP and USD LIBOR term structures obtained from [12], [13], and the GBP/USD foreign exchange rate obtained from [33]. The descriptive statistics of the data was as illustrated in Table 2 below.

Table 2. Descriptive statistics of the data.

\begin{tabular}{ccc}
\hline Data & Mean & Std. Dev \\
\hline ON GBP LIBOR & 1.012771 & 1.483388 \\
6M GBP LIBOR & 1.420781 & 1.611518 \\
ON USD LIBOR & 0.627407 & 1.040560 \\
6M USD LIBOR & 1.091000 & 1.049520 \\
GBP/USD FX Rate & 1.560398 & 0.188801 \\
\hline
\end{tabular}




\subsection{Calibration of the MCCCLMM Parameters}

Our MCCCLMM model was calibrated to match the cap market prices provided by [36]. The parameters estimated were as summarised in the subsections of this section. For presentability purposes, in this paper, the parameter estimates stated were rounded off to the nearest 5 decimal places. However, the values used while pricing were not rounded off.

\subsubsection{Estimation of the MCCCLMM Correlation Parameters}

The correlation parameters were estimated using Equation (7) using data collected from [12] [13]. These parameter estimates were as summarized in Table 3.

\subsubsection{Estimation of the Foreign Exchange Rate Volatility Parameter}

The foreign exchange rate volatility parameter was estimated using the formula expressed in Equation (12) from historical rates collected from [33]. The $\sigma_{X}$ estimate was as summarised in Table 4 . We assumed that $\Delta t=0.5$.

\subsubsection{Forward LIBOR Volatility Estimates}

Just as described in Section 2.5.3, we assumed that the S parameters fit the market cap volatilities. The S parameters for the GBP and USD markets are as summarized in Table 5 and Table 6 respectively. The GBP LIBOR market volatility parameter $\gamma_{f L}$ was extracted directly from actual GBP ATM cap prices dataset struck on 2/1/2018 and summarized in Table 5.

Table 3. MCCCLMM correlation parameter estimates from historical rates.

\begin{tabular}{cc}
\hline Parameter & Estimate \\
\hline$\rho_{d D}^{d L}$ & 0.95207 \\
$\rho_{f D}^{f L}$ & 0.98662 \\
$\rho_{x x}^{f L}$ & 0.74244 \\
$\rho_{d D}^{f D}$ & 0.85917 \\
$\rho_{d L}^{f D}$ & 0.89546 \\
$\rho_{d D}^{f L}$ & 0.79783 \\
$\rho_{d L}^{f L}$ & 0.86769 \\
$\rho_{x x}^{f D}$ & 0.74092 \\
$\rho_{x x}^{d D}$ & 0.50421 \\
$\rho_{x x}^{d L}$ & 0.44993 \\
\hline
\end{tabular}

Table 4. $\sigma_{X}$ parameter estimate from historical rates.

\begin{tabular}{cc}
\hline Parameter & Estimate \\
\hline$\sigma_{X}$ & 0.13260 \\
\hline
\end{tabular}


Table 5. $\gamma_{f L}$ estimate.

\begin{tabular}{ccccccccccc}
\hline Term (Yrs) & 1 & 2 & 3 & 4 & 5 & 6 & 7 & 8 & 9 & 10 \\
\hline$\gamma_{f L}$ & 39.28 & 41.62 & 46.89 & 51.84 & 55.42 & 57.90 & 59.43 & 60.18 & 60.18 & 59.76
\end{tabular}

Table 6. $\gamma_{d L}$ estimate (\%).

\begin{tabular}{ccccccccccc}
\hline Term (Yrs) & 1 & 2 & 3 & 4 & 5 & 6 & 7 & 8 & 9 & 10 \\
\hline$\gamma_{d L}$ & 15.38 & 18.81 & 21.73 & 23.92 & 25.63 & 26.59 & 27.14 & 27.55 & 27.75 & 27.86
\end{tabular}

The USD LIBOR volatility parameter $\gamma_{d L}$ was also extracted directly from actual USD ATM cap prices dataset struck on 2/1/2018 and summarized in Table 6.

\subsubsection{Calibrating the $\sigma_{d D}$ Parameter}

The $\sigma_{d D}$ parameter was calibrated using Equation (17) to exactly match the actual USD ATM cap prices. The optimal values of $\sigma_{d D}$ were as summarized in Table 7.

\subsubsection{Calibrating the $\sigma_{f D}$ Parameters}

The $\sigma_{f D}$ parameter was calibrated using Equation (17) to exactly match the actual GBP ATM cap prices. The optimal values of $\sigma_{f D}$ were as summarized in Table 8.

\subsection{The Discount Curve}

The US treasury and UK gilt yields collected from [35] and [34] respectively were assumed to be the risk free rates. The USD and GBP yield curves were then estimated using the NSS method.

\subsubsection{Bootstrapping of the USD and GBP Yield Curves}

The USD and GBP yield curves extracted from [35] and [34] respectively were bootstrapped using the NSS method described in Section 2.6. The estimated NSS model parameters of the two curves were as summarised in Table 9.

Figure 3 and Figure 4 below show how the NSS yield curve matches the actual yields.

\subsubsection{Estimation of the Discount Curve}

The USD or GBP discount factors were estimated using the formula in Equation (21) where $y(t)$ was taken to be the USD or GBP NSS yields. The estimated USD and GBP discount curves were then plotted in Figure 5 and Figure 6.

\subsection{Valuation of Caps and Floors in the Black MCCCLMM Formula}

Using the calibrated model parameters, the GBP and USD caps and floors were priced using the Black like formula expressed in Section 2.5.4. 
USD NSS Yield Curve Estimation

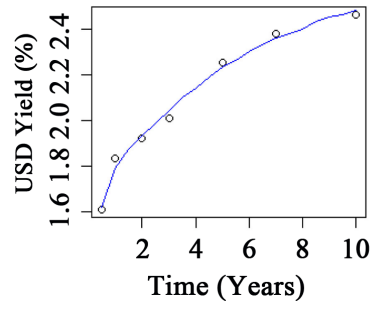

Figure 3. USD NSS yield curve.

GBP NSS Yield Curve Estimation

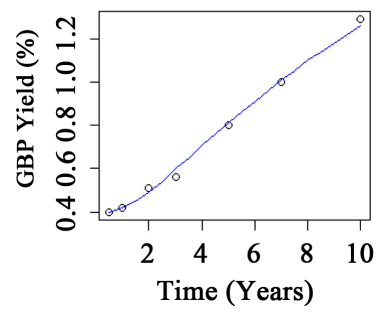

Figure 4. GBP NSS yield curve.

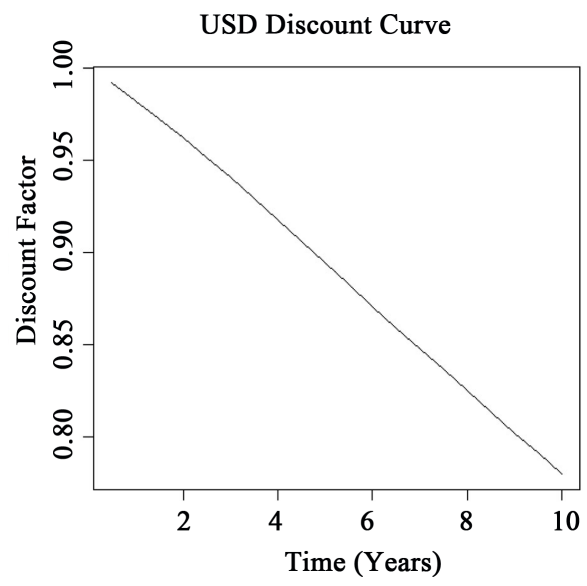

Figure 5. USD discount curve.

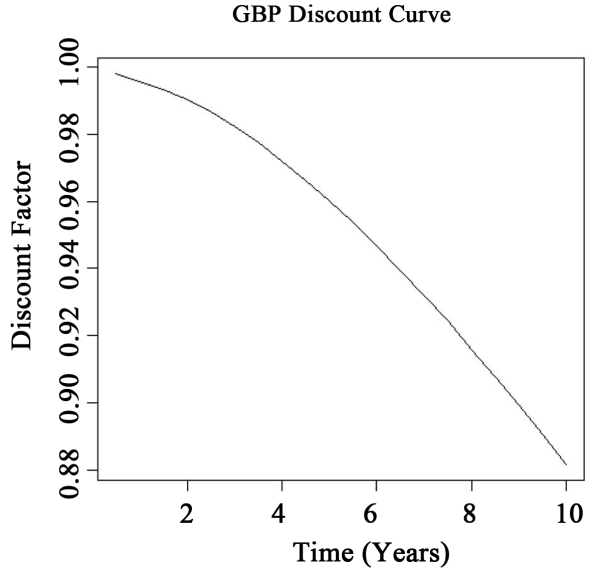

Figure 6. GBP discount curve. 
Table 7. $\sigma_{d D}$ estimate.

\begin{tabular}{cc}
\hline Term (Yrs) & $\sigma_{d D}$ \\
\hline 1 & 0.90115 \\
2 & 0.99222 \\
3 & 0.73135 \\
4 & 0.57991 \\
5 & 0.48292 \\
6 & 0.41020 \\
7 & 0.36683 \\
8 & 0.32919 \\
9 & 0.30060 \\
10 & 0.27847 \\
\hline
\end{tabular}

Table 8. $\sigma_{f D}$ estimate.

\begin{tabular}{cc}
\hline Term $($ Yrs $)$ & $\sigma_{f D}$ \\
\hline 1 & 0.69920 \\
2 & 0.88745 \\
3 & 0.72613 \\
4 & 0.58257 \\
5 & 0.48707 \\
6 & 0.31340 \\
7 & 0.36333 \\
8 & 0.32514 \\
9 & 0.29623 \\
10 & 0.27347 \\
\hline
\end{tabular}

Table 9. NSS parameter estimates.

\begin{tabular}{ccc}
\hline Parameter & USD Estimates & GBP Estimates \\
\hline$\beta_{0}$ & 0.02801 & 0.02546 \\
$\beta_{1}$ & -0.01687 & -0.02149 \\
$\beta_{2}$ & 0.01250 & -0.01153 \\
$\beta_{3}$ & -0.02377 & -0.01152 \\
$\lambda_{1}$ & 0.56940 & 3.13672 \\
$\lambda_{2}$ & 1.22308 & 3.55075 \\
\hline
\end{tabular}

\subsubsection{USD Cap and Floor Prices}

USD ATM Cap and Floor prices for options struck on 2/1/2018, with a range of maturities, were calculated using the calibrated Black-like formula expressed in Equation (17). Table 10 gives the results of the USD ATM Cap and Floor prices in basis points (bp). 
Table 10. Black USD ATM CAP and FLOOR prices in bp struck on 2/1/2018.

\begin{tabular}{cccc}
\hline Maturity Date & Strike Price $(\%)$ & Cap Price $(\$)$ & Floor Price $(\$)$ \\
\hline $2 / 1 / 2019$ & 1.961 & 14.4 & 7.4 \\
$2 / 1 / 2020$ & 2.126 & 60.2 & 15.9 \\
$4 / 1 / 2021$ & 2.199 & 129.0 & 28.7 \\
$3 / 1 / 2022$ & 2.242 & 218.2 & 46.0 \\
$2 / 1 / 2023$ & 2.273 & 325.3 & 67.7 \\
$2 / 1 / 2024$ & 2.303 & 442.8 & 93.9 \\
$2 / 1 / 2025$ & 2.334 & 571.4 & 123.4 \\
$2 / 1 / 2026$ & 2.365 & 706.5 & 156.4 \\
$4 / 1 / 2027$ & 2.394 & 847.0 & 192.4 \\
$3 / 1 / 2028$ & 2.420 & 992.4 & 230.7 \\
\hline
\end{tabular}

\subsubsection{GBP Cap and Floor Prices}

GBP ATM Cap and Floor prices for options struck on 2/1/2018, with a range of maturities, were calculated using the calibrated Black-like formula expressed in Equation (17). Table 11 gives the results of the GBP ATM Cap and Floor prices in basis points (bp).

\subsection{Valuation of Quanto Caps and Floors in the Black MCCCLMM Formula}

ATM Quanto Cap and Floor prices for options struck on 2/1/2018 with a range of maturities were calculated using the calibrated Black MCCCLMM Quanto Caplet or Floorlet Formula expressed in Theorem 1. Table 12 gives the results of the Quanto ATM Cap and Floor prices in basis points (b.p).

Where $X^{0}$ was taken to be the GBP/USD foreign exchange rate closing price on $2 / 1 / 2018$ given by 1.3588 . The time evolution of the quanto option prices is as shown in Figure 7.

From Figure 7 it can be seen that for the 10 year period, the quanto caps are expected to be sold at a higher price compared to the quanto floors. However, it was noted that the rate of appreciation of the floor prices is quite high such that it is expected that they will eventually overtake the cap prices as time goes by.

\subsection{Simulation of Cap and Floor Prices}

The domestic and foreign LIBOR model dynamics were first discretized using the Euler scheme.

\subsubsection{Generation of the Correlated Wiener Processes}

The correlation matrix of our observed data was found to be:

$$
\Sigma=\left(\begin{array}{lllll}
1.00000 & 0.95207 & 0.85917 & 0.79783 & 0.50421 \\
0.95207 & 1.00000 & 0.89546 & 0.86769 & 0.44993 \\
0.85917 & 0.89546 & 1.00000 & 0.98662 & 0.74092 \\
0.79783 & 0.86769 & 0.98662 & 1.00000 & 0.74244 \\
0.50421 & 0.44993 & 0.74092 & 0.74244 & 1.00000
\end{array}\right)
$$




\section{QUANTO OPTION PRICES}

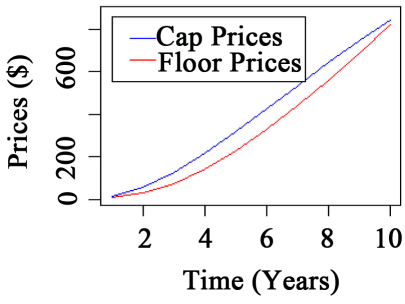

Figure 7. Quanto option prices evolution.

Table 11. Black GBP ATM CAP and FLOOR prices in bp struck on 2/1/2018.

\begin{tabular}{cccc}
\hline Maturity Date & Strike Price $(\%)$ & Cap Price $(\mathfrak{E})$ & Floor Price $(\mathfrak{E})$ \\
\hline $2 / 1 / 2019$ & 0.662 & 11.8 & 7.1 \\
$2 / 1 / 2020$ & 0.800 & 50.2 & 16.1 \\
$4 / 1 / 2021$ & 0.903 & 118.9 & 30.0 \\
$3 / 1 / 2022$ & 0.982 & 216.6 & 50.9 \\
$2 / 1 / 2023$ & 1.052 & 341.2 & 79.3 \\
$2 / 1 / 2024$ & 1.111 & 485.5 & 115.5 \\
$2 / 1 / 2025$ & 1.164 & 647.5 & 158.5 \\
$2 / 1 / 2026$ & 1.214 & 822.4 & 207.8 \\
$4 / 1 / 2027$ & 1.261 & 1006.0 & 262.2 \\
$3 / 1 / 2028$ & 1.305 & 1195.4 & 320.9 \\
\hline
\end{tabular}

Table 12. Black quanto ATM CAP and FLOOR prices struck on 2/1/2018.

\begin{tabular}{cccc}
\hline Maturity Date & Strike Price $(\%)$ & Cap Price $(\$)$ & Floor Price $(\$)$ \\
\hline $2 / 1 / 2019$ & 0.662 & 14.1 & 10.6 \\
$2 / 1 / 2020$ & 0.800 & 57.0 & 24.6 \\
$4 / 1 / 2021$ & 0.903 & 128.2 & 46.8 \\
$3 / 1 / 2022$ & 0.982 & 221.3 & 79.9 \\
$2 / 1 / 2023$ & 1.052 & 330.5 & 124.4 \\
$2 / 1 / 2024$ & 1.111 & 446.9 & 180.2 \\
$2 / 1 / 2025$ & 1.164 & 567.5 & 245.6 \\
$2 / 1 / 2026$ & 1.214 & 688.2 & 319.4 \\
$4 / 1 / 2027$ & 1.261 & 806.3 & 400.0 \\
$3 / 1 / 2028$ & 1.305 & 920.5 & 486.1 \\
\hline
\end{tabular}

The lower triangular matrix defined in Equation (25) was then calculated and found to be:

$$
A=\left(\begin{array}{ccccc}
1.00000 & 0.00000 & 0.00000 & 0.00000 & 0.00000 \\
0.95207 & 0.30587 & 0.00000 & 0.00000 & 0.00000 \\
0.85917 & 0.25325 & 0.44462 & 0.00000 & 0.00000 \\
0.79783 & 0.35339 & 0.47601 & 0.10949 & 0.00000 \\
0.50421 & -0.09844 & 0.74816 & 0.17190 & 0.38312
\end{array}\right)
$$

The correlated Wiener process was then estimated as: 


$$
\left(\begin{array}{l}
\mathrm{d} W_{d D}(t) \\
\mathrm{d} W_{d L}(t) \\
\mathrm{d} W_{f D}(t) \\
\mathrm{d} W_{f L}(t) \\
\mathrm{d} W_{x x}(t)
\end{array}\right)=\sqrt{0.5}\left(\begin{array}{ccccc}
1.00000 & 0.00000 & 0.00000 & 0.00000 & 0.00000 \\
0.95207 & 0.30587 & 0.00000 & 0.00000 & 0.00000 \\
0.85917 & 0.25325 & 0.44462 & 0.00000 & 0.00000 \\
0.79783 & 0.35339 & 0.47601 & 0.10949 & 0.00000 \\
0.50421 & -0.09844 & 0.74816 & 0.17190 & 0.38312
\end{array}\right)\left(\begin{array}{l}
Z_{1} \\
Z_{2} \\
Z_{3} \\
Z_{4} \\
Z_{5}
\end{array}\right)(36)
$$

where $Z_{i} ; i \in\{1,2,3,4,5\}$ are independent standard normal random variables.

\subsubsection{Simulation of USD Cap and Floor Prices}

The formula expressed in Equation (28) was used to simulate USD cap or floor prices at time, $t . N_{d}=\$ 10000 . P_{d}^{D}(t,$.$) is the risk-free discount factor asso-$ ciated with the USD discount curve. The mean simulated USD at the money (ATM) Cap and Floor prices stuck on 2/1/2018 were as summarised in Table 13.

\subsubsection{Simulation of GBP Cap and Floor Prices}

The formula expressed in Equation (30) was used to simulate GBP cap or floor prices at time, $t . N_{f}=£ 10000, P_{f}^{D}(t,$.$) is the GBP risk-free discount factor$ associated with the U.K discount curve, $\Delta t=0.5$. The mean simulated GBP at the money (ATM) Cap and Floor prices stuck on 2/1/2018 were as summarised in Table 14.

Table 13. Simulated USD ATM CAP and FLOOR prices struck on 2/1/2018.

\begin{tabular}{cccc}
\hline Maturity Date & Strike Price $(\%)$ & Cap Price $(\$)$ & Floor Price $(\$)$ \\
\hline $2 / 1 / 2019$ & 1.961 & 14.4 & 7.4 \\
$2 / 1 / 2020$ & 2.126 & 60.1 & 15.9 \\
$4 / 1 / 2021$ & 2.199 & 129.0 & 28.7 \\
$3 / 1 / 2022$ & 2.242 & 219.0 & 46.0 \\
$2 / 1 / 2023$ & 2.273 & 325.6 & 67.7 \\
$2 / 1 / 2024$ & 2.303 & 443.8 & 93.7 \\
$2 / 1 / 2025$ & 2.334 & 572.8 & 123.4 \\
$2 / 1 / 2026$ & 2.365 & 706.4 & 157.0 \\
$4 / 1 / 2027$ & 2.394 & 847.3 & 192.5 \\
$3 / 1 / 2028$ & 2.420 & 992.0 & 230.5 \\
\hline
\end{tabular}

Table 14. Simulated GBP ATM CAP and FLOOR prices stuck on 2/1/2018.

\begin{tabular}{cccc}
\hline Maturity Date & Strike Price $(\%)$ & Cap Price $(\mathfrak{E})$ & Floor Price $(\mathfrak{E})$ \\
\hline $2 / 1 / 2019$ & 0.662 & 11.7 & 7.1 \\
$2 / 1 / 2020$ & 0.800 & 50.4 & 16.1 \\
$4 / 1 / 2021$ & 0.903 & 119.1 & 30.0 \\
$3 / 1 / 2022$ & 0.982 & 216.6 & 50.9 \\
$2 / 1 / 2023$ & 1.052 & 341.4 & 79.2 \\
$2 / 1 / 2024$ & 1.111 & 484.7 & 115.6 \\
$2 / 1 / 2025$ & 1.164 & 648.0 & 158.6 \\
$2 / 1 / 2026$ & 1.214 & 823.7 & 207.9 \\
$4 / 1 / 2027$ & 1.261 & 1008.4 & 262.3 \\
$3 / 1 / 2028$ & 1.305 & 1188.0 & 320.8 \\
\hline
\end{tabular}




\subsubsection{Simulation of Quanto Cap and Floor Prices}

The formula expressed in Equation (32) was used to simulate quanto cap or floor prices at time, $t . N_{f}=£ 10000, P_{d}^{D}(t,$.$) is the USD risk-free discount$ factor associated with the US discount curve, $\Delta t=0.5$. The mean simulated at the money (ATM) quanto Cap and Floor prices stuck on 2/1/2018 were as summarised in Table 15.

\subsubsection{Comparison between the Black MCCCLMM Formulas and the Monte Carlo Simulations}

The Black MCCCLMM cap and floor prices were compared to those estimated via the Monte Carlo simulation technique so as to ascertain the pricing accuracy of the Black MCCCLMM formulas using the mean absolute percentage error (MAPE) technique. The MAPE results were as given in Table 16. According to [38], if MAPE $\leq 10 \%$, then the model is considered to be highly accurate. If $10 \%<$ MAPE $\leq 20 \%$, then the model is considered to be a good model. If $20 \%<$ MAPE $\leq 50 \%$, then the model is considered to be reasonable, and if MAPE $>50 \%$ then the model is taken to be inaccurate. Hence from Table 16, we can see that the simulated results can be considered to be highly accurate when compared to the Black MCCCLMM formula as the MAPEs of all the options priced lie below $1 \%$. Hence it was concluded that the two models are almost similar which is a good result. Hence the derived Black MCCCLMM model is reliable.

\subsection{Cap and Floor Volatility Surfaces}

Using the calibrated parameters, different USD, GBP and Quanto Cap and Floor prices were estimated under different strike price assumptions. The cap volatility

Table 15. Simulated quanto ATM CAP and FLOOR prices struck on 2/1/2018.

\begin{tabular}{cccc}
\hline Maturity Date & Strike Price $(\%)$ & Cap Price $(\$)$ & Floor Price $(\$)$ \\
\hline $2 / 1 / 2019$ & 0.662 & 14.1 & 10.6 \\
$2 / 1 / 2020$ & 0.800 & 57.0 & 24.6 \\
$4 / 1 / 2021$ & 0.903 & 128.6 & 46.8 \\
$3 / 1 / 2022$ & 0.982 & 220.0 & 80.1 \\
$2 / 1 / 2023$ & 1.052 & 330.5 & 124.4 \\
$2 / 1 / 2024$ & 1.111 & 448.0 & 180.3 \\
$2 / 1 / 2025$ & 1.164 & 569.4 & 245.6 \\
$2 / 1 / 2026$ & 1.214 & 685.2 & 319.4 \\
$4 / 1 / 2027$ & 1.261 & 804.0 & 400.1 \\
$3 / 1 / 2028$ & 1.305 & 919.1 & 485.8
\end{tabular}

Table 16. MAPE results of the quanto cap and floor prices.

\begin{tabular}{cc}
\hline Quanto Type & MAPE (\%) \\
\hline Cap & 0.2354 \\
Floor & 0.0393
\end{tabular}


surfaces of the USD, GBP and GBP/USD Quanto options were as shown in Figure 8 below: From Figure 8, we noticed that the cap volatility surfaces of the 3 different options had roughly the same shape. It was also noted that in general over the three options, when the strike prices increase, the CAP prices reduced. In addition to this, cap prices increased with maturity.

The Floor volatility surfaces of the USD, GBP and GBP/USD Quanto options were as shown in Figure 9 below: From Figure 9, we noticed that the floor volatility surfaces of the 3 different options also had roughly the same shape. It was also noted that in general, when the strike prices increase, the floor prices also increase. In addition to this, floor prices increased with maturity.

\section{Conclusions}

This study aimed at pricing quanto caps and floors using the multi-curve cross-currency LIBOR market model dynamics. It focused on calibrating the model to real world USD and GBP cap market prices. The MCCCLMM correlation and foreign exchange rate volatility parameters were estimated from 10 years historical market rates. The generated payoffs were later on discounted using USD treasury rates. The estimated MCCCLMM parameters were then used to price quanto cap and floor options both under the derived Black MCCCLMM quanto caplet and floorlet formula and also via 100,000 Monte Carlo simulations. The two methods were then compared using the mean absolute percentage error (MAPE) to ascertain the pricing accuracy of the derived model. The MAPEs between the two models were found to lie below $1 \%$ hence

USD CAP Prices in b.p.

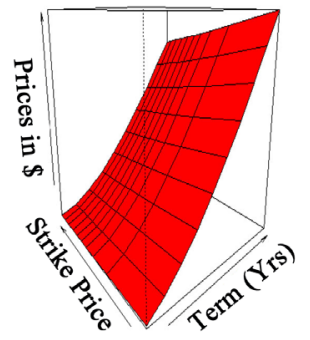

GBP CAP Prices in b.p.

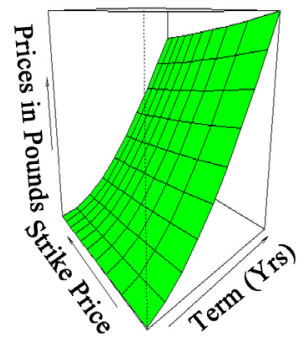

QUANTO CAP Prices in b.p.

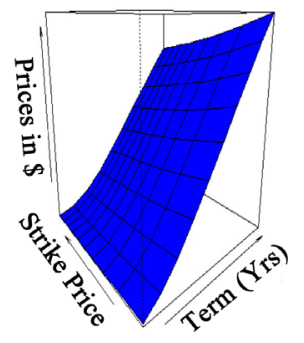

Figure 8. Cap volatility surfaces.

USD FLOOR Prices in b.p.

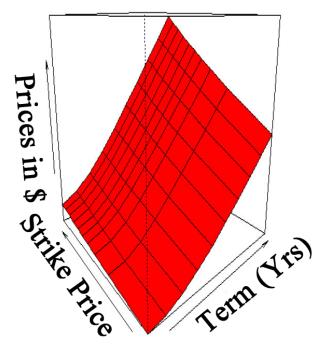

GBP FLOOR Prices in b.p. QUANTO FLOOR Prices in b.p.

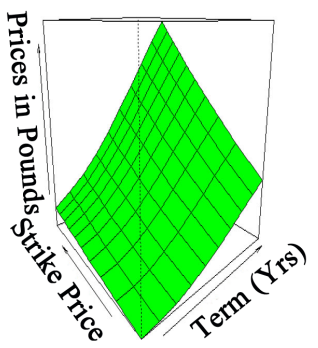

Figure 9. Floor volatility surfaces. 
deeming the two models as similar implying that the derived MCCCLMM quanto caplet or floorlet formula is highly accurate. The volatility surfaces of the quanto options were similar to those of the GBP and USD options.

It should be noted that due to data availability constraints, the MCCCLMM parameters in this paper were neither calibrated using swaptions nor discounted using overnight indexed swap (OIS) rates. Hence in this paper we were constrained on pricing our caps and floors on a single tenor (6 months). Also, the model was discounted using treasury rates as they are also proxies for the risk-free rate. In the future, it is advisable for the model to be discounted using the OIS rates and compare between the two methods.

\section{Acknowledgements}

We thank the Editor and the reviewers for their comments. The first author acknowledges financial support from Pan African University Institute of Basic and Applied Sciences Scholarship. This support is greatly appreciated.

\section{Conflicts of Interest}

The authors declare that they have no conflicts of interest.

\section{References}

[1] Papapantoleon, A. (2010) Old and New Approaches to Libor Modeling. Statistica Neerlandica, 64, 257-275. https://doi.org/10.1111/j.1467-9574.2010.00458.x

[2] Vasicek, O. (1977) An Equilibrium Characterization of the Term Structure. Journal of Financial Economics, 5, 177-188. https://doi.org/10.1016/0304-405X(77)90016-2

[3] Hull, J. and White, A. (1990) Pricing Interest-Rate-Derivative Securities. The Review of Financial Studies, 3, 573-592. https://doi.org/10.1093/rfs/3.4.573

[4] Chan, K.C., Karolyi, G.A., Longstaff, F.A. and Sanders, A.B. (1992) An Empirical Comparison of Alternative Models of the Short-Term Interest Rate. The Journal of Finance, 47, 1209-1227. https://doi.org/10.1111/j.1540-6261.1992.tb04011.x

[5] Andersen, T.G. and Lund, J. (1997) Estimating Continuous-Time Stochastic Volatility Models of the Short-Term Interest Rate. Journal of Econometrics, 77, 343-377. https://doi.org/10.1016/S0304-4076(96)01819-2

[6] Cox, J.C., Ingersoll Jr., J.E. and Ross, S.A. (1985) A Theory of the Term Structure of Interest Rates. Econometrica, 53, 321-346.

[7] Heath, D., Jarrow, R. and Morton, A. (1992) Bond Pricing and the Term Structure of Interest Rates: A New Methodology for Contingent Claims Valuation. Econometrica: Journal of the Econometric Society, 60, 77-105. https://doi.org/10.2307/2951677

[8] Brace, A., Musiela, M. and Ģatarek, D. (1997) The Market Model of Interest Rate Dynamics. Mathematical Finance, 7, 127-155. https://doi.org/10.1111/1467-9965.00028

[9] Miltersen, K.R., Sandmann, K. and Sondermann, D. (1997) Closed Form Solutions for Term Structure Derivatives with Log-Normal Interest Rates. The Journal of Finance, 52, 409-430. https://doi.org/10.1111/j.1540-6261.1997.tb03823.x

[10] Jamshidian, F. (1997) LIBOR and Swap Market Models and Measures. Finance and 
Stochastics, 1, 293-330. https://doi.org/10.1007/s007800050026

[11] Henrard, M. (2007) The Irony in the Derivatives Discounting. SSRN Electronic Journal. https://doi.org/10.2139/ssrn.970509

[12] IBORate (2018) USD LIBOR History, 2018. http://www.iborate.com/usd-libor/

[13] IBORate (2018) GBP LIBOR History, 2018. http://www.iborate.com/gbp-libor/

[14] Ametrano, F.M. and Bianchetti, M. (2013) Everything You Always Wanted to Know about Multiple Interest Rate Curve Bootstrapping but Were Afraid to Ask. https://doi.org/10.2139/ssrn.2219548

[15] Bianchetti, M. (2012) Two Curves, One Price: Pricing and Hedging Interest Rate Derivatives Decoupling Forwarding and Discounting Yield Curves. arXiv: 0905.2770.

[16] Bianchetti, M. and Carlicchi, M. (2011) Interest Rates after the Credit Crunch: Multiple Curve Vanilla Derivatives and SABR. Quantitative Finance, 1-26. https://doi.org/10.2139/ssrn.1783070

[17] Crépey, S., Grbac, Z. and Nguyen, H.-N. (2012) A Multiple-Curve HJM Model of Interbank Risk. Mathematics and Financial Economics, 6, 155-190. https://doi.org/10.1007/s11579-012-0083-4

[18] Cuchiero, C., Fontana, C. and Gnoatto, A. (2016) A General HJM Framework for Multiple Yield Curve Modeling. Finance and Stochastics, 20, 267-320. https://doi.org/10.1007/s00780-016-0291-5

[19] Grasselli, M. and Miglietta, G. (2016) A Flexible Spot Multiple-Curve Model. Quantitative Finance, 16, 1465-1477. https://doi.org/10.1080/14697688.2015.1108521

[20] Grbac, Z., Papapantoleon, A., Schoenmakers, J. and Skovmand, D. (2015) Affine LIBOR Models with Multiple Curves: Theory, Examples and Calibration. SIAM Journal on Financial Mathematics, 6, 984-1025. https://doi.org/10.1137/15M1011731

[21] Henrard, M. (2010) The Irony in Derivatives Discounting Part II: The Crisis. Wilmott Journal, 2, 301-316. https://doi.org/10.1002/wilj.39

[22] Henrard, M. (2014) Interest Rate Modelling in the Multi-Curve Framework: Foundations, Evolution and Implementation. Springer, New York. https://doi.org/10.1057/9781137374660

[23] Hess, M. (2016) An Arithmetic Pure-Jump Multi-Curve Interest Rate Model. Browser Download This Paper. https://doi.org/10.2139/ssrn.2817816

[24] Mercurio, F. (2009) Interest Rates and the Credit Crunch: New Formulas and Market Models. Bloomberg Portfolio Research Paper.

[25] Mercurio, F. (2010) Libor Market Models with Stochastic Basis. Bloomberg Education and Quantitative Research Paper. https://doi.org/10.2139/ssrn.1563685

[26] Mercurio, F. (2017) The Present of Futures: Valuing Eurodollar-Futures Convexity Adjustments in a Multi-Curve World. SSRN Electronic Journal. https://doi.org/10.2139/ssrn.2987832

[27] Wamwea, C., Ngare, P. and Le Doux Mbele Bidima, M. (2019) A Multicurve Cross-Currency Libor Market Model. Journal of Applied Mathematics, 2019, Article ID: 8246578. https://doi.org/10.1155/2019/8246578

[28] Wu, L. (2002) Fast at-the-Money Calibration of the Libor Market Model Using Lagrange Multipliers. Journal of Computational Finance, 6, 39-77. https://doi.org/10.21314/JCF.2002.093

[29] Lagnado, R. and Osher, S. (1997) A Technique for Calibrating Derivative Security 
Pricing Models: Numerical Solution of an Inverse Problem. Journal of Computational Finance, 1, 14-25. https://doi.org/10.21314/JCF.1997.002

[30] Brigo, D., Capitani, C. and Mercurio, F. (2001) On the Joint Calibration of the LIBOR Market Model to Caps and Swaptions Market Volatilities.

[31] Riga, C. (2011) The Libor Market Model: From Theory to Calibration. PhD Thesis.

[32] Sidenius, J. (2000) Libor Market Models in Practice. Journal of Computational Finance, 3, 5-26. https://doi.org/10.21314/JCF.2000.044

[33] Fusion Media Limited (2018) GBP/USD-British Pound US Dollar. https://www.investing.com/currencies/gbp-usd

[34] Fusion Media Limited (2018) United Kingdom-Government Bonds. https://www.investing.com/rates-bonds/uk-government-bonds? maturity from $=40$ maturity to $=310$

[35] Fusion Media Limited (2018) United States-Government Bonds. https://www.investing.com/rates-bonds/usa-government-bonds? maturity from $=40$ maturity to $=290$

[36] TPICAP (2018) Tullett Prebon Information, Interest Rate Options. https://www.tpicap.com/

[37] Dmouj, A. (2006) Stock Price Modelling: Theory and Practice. Master's Thesis, Vrije Universiteit, ¡Amsterdam.

[38] Abidin, S.N.Z. and Jaffar, M.M. (2014) Forecasting Share Prices of Small Size Companies in Bursa Malaysia Using Geometric Brownian Motion. Applied Mathematics \& Information Sciences, 8, 107-112. https://doi.org/10.12785/amis/080112

[39] Kloeden, P. and Platen, E. (1992) Numerical Solution of Stochastic Differential Equations. Springer, New York. https://doi.org/10.1007/978-3-662-12616-5

[40] Benner, W., Zyapkov, L. and Jortzik, S. (2009) A Multi-Factor Cross-Currency Libor Market Model. The Journal of Derivatives, 16, 53-71.

https://doi.org/10.3905/JOD.2009.16.4.053 


\section{Appendix}

\section{A. Derivation of the Black MCCCLMM Quanto Caplet Formula}

Assuming the parameters are constant such that the dynamics of the foreign risky LIBOR under the spot domestic risk-neutral measure can be expressed as follows:

$$
\frac{\mathrm{d} L_{f}(t, T)}{L_{f}(t, T)}=\left(\rho_{f D}^{f L} * \sigma_{d D}-\rho_{x x}^{f L} * \sigma_{X}\right) * \gamma_{f L} * \mathrm{~d} t+\gamma_{f L} * \mathrm{~d} W_{f L}(t)
$$

Then the price at time $t$ of a quanto caplet struck on this LIBOR is given by:

$$
\begin{aligned}
& Q \operatorname{Cplt}\left(t, T, K_{f}, X^{0}, N_{f}\right) \\
= & \tau N_{f} X^{0} P_{d}^{D}(t, T) E^{\mathbb{Q}^{D}}\left[\left(L_{f}(T, T)-K_{f}\right)^{+} \mid \mathcal{F}_{t}\right] \\
= & \tau N_{f} X^{0} P_{d}^{D}(t, T) E^{\mathbb{Q}^{D}}\left[\left(L_{f}(T, T)-K_{f}\right) I_{A} \mid \mathcal{F}_{t}\right] \\
= & \tau N_{f} X^{0} P_{d}^{D}(t, T) \underbrace{E^{\mathbb{Q}^{D}}\left[L_{f}(T, T) I_{A} \mid \mathcal{F}_{t}\right]}_{M} \\
& -\tau N_{f} X^{0} P_{d}^{D}(t, T) \underbrace{E^{\mathbb{Q}^{D}\left[K_{f} I_{A} \mid \mathcal{F}_{t}\right]}}_{N}
\end{aligned}
$$

where $I_{A}$ is an indicator function such that

$$
I_{A}=\left\{\begin{array}{cc}
1 & \text { if } L_{f}(T, T)-K_{f}>0 \\
0 & \text { elsewhere }
\end{array}\right.
$$

$M$ and $N$ were then solved separately and the results inserted back into Equation (38) at the end.

The risky foreign LIBOR defined in Equation (37) under the spot domestic risk neutral measure $\mathbb{Q}^{D}$ has a solution given by:

$$
L_{f}(T, T)=L_{f}(t, T) \mathrm{e}^{\left(\left(\rho_{f D}^{f L} * \sigma_{d D}-\rho_{x x}^{f L} * \sigma_{X}\right) * \gamma_{f L}-\frac{1}{2} * \gamma_{f L}^{2}\right)(T-t)+\gamma_{f L}\left(W_{f L}(T)-W_{f L}(t)\right)}
$$

Solving for $M$ : We saw that

$$
\begin{aligned}
M & =\mathbb{E}^{\mathbb{Q}^{D}}\left[L_{f}(T, T) I_{A} \mid \mathcal{F}_{t}\right] \\
& =\mathbb{E}^{\mathbb{Q}^{D}}\left[L_{f}(t, T) \mathrm{e}^{\left(\left(\rho_{f D}^{f L} * \sigma_{d D}-\rho_{x x}^{f L} * \sigma_{X}\right) * \gamma_{f L}-\frac{1}{2} * \gamma_{f L}^{2}\right)(T-t)+\gamma_{f L}\left(W_{f L}(T)-W_{\mathcal{L}}(t)\right)} I_{A} \mid \mathcal{F}_{t}\right] \\
& =L_{f}(t, T) \mathrm{e}^{\left(\rho_{f D}^{f L} * \sigma_{d D}-\rho_{x x}^{f L} * \sigma_{X}\right) * \gamma_{f L} *(T-t)} * \mathbb{E}^{\mathbb{Q}^{D}}\left[\mathrm{e}^{-\frac{1}{2} * \gamma_{\mathcal{L}}^{2} *(T-t)+\gamma_{f L}\left(W_{f L}(T)-W_{f L}(t)\right)} I_{A} \mid \mathcal{F}_{t}\right]
\end{aligned}
$$

Defining a new probability measure $V$ given by the Radon Nikodym derivative

$$
\frac{\mathrm{d} V}{\mathrm{~d} Q^{D}}=\mathrm{e}^{-\frac{1}{2} * \gamma_{L}^{2} *(T-t)+\gamma_{f L}\left(W_{f L}(T)-W_{f L}(t)\right)}
$$

such that

$$
\mathrm{d} W_{f L}^{V}(t)=\mathrm{d} W_{f L}(t)-\gamma_{f L} * \mathrm{~d} t
$$


then

$$
\begin{aligned}
& M=L_{f}(t, T) \mathrm{e}^{\left(\rho_{f D}^{f J} * \sigma_{d D}-\rho_{x x}^{f L} * \sigma_{X}\right) * \gamma_{f L} *(T-t)} * \mathbb{E}^{\mathbb{Q}^{D}}\left[\mathrm{e}^{\frac{1}{2} * \gamma_{L}^{2} *(T-t)+\gamma_{f L}\left(W_{f L}(T)-W_{f L}(t)\right)} I_{A} \mid \mathcal{F}_{t}\right] \\
& =L_{f}(t, T) \mathrm{e}^{\left(\rho_{f D}^{f L} * \sigma_{d D}-\rho_{x x}^{f L} * \sigma_{X}\right) * \gamma_{f L} *(T-t)} \mathbb{E}^{V}\left[I_{A} \mid \mathcal{F}_{t}\right] \\
& =L_{f}(t, T) \mathrm{e}^{\left(\rho_{f D}^{f} * \sigma_{d D}-\rho_{x x}^{f f} * \sigma_{X}\right) * \gamma_{\mathcal{L}} *(T-t)} * 0 * \operatorname{Pr}^{\mathbb{V}}\left(L_{f}(T, T)-K_{f} \leq 0 \mid \mathcal{F}_{t}\right) \\
& +L_{f}(t, T) \mathrm{e}^{\left(\rho_{f D}^{f f} * \sigma_{d D}-\rho_{x x}^{f L} * \sigma_{X}\right) * \gamma_{f L} *(T-t)} * 1 * \operatorname{Pr}^{\mathbb{V}}\left(L_{f}(T, T)-K_{f}>0 \mid \mathcal{F}_{t}\right) \\
& =L_{f}(t, T) \mathrm{e}^{\left(\rho_{f D}^{f L} * \sigma_{d D}-\rho_{x x}^{f L} * \sigma_{X}\right) * \gamma_{L L} *(T-t)} * 1 * \operatorname{Pr}^{\mathbb{V}}\left(L_{f}(T, T)-K_{f}>0 \mid \mathcal{F}_{t}\right)
\end{aligned}
$$

Now solving for $\operatorname{Pr}^{\mathbb{V}}\left(L_{f}(T, T)-K_{f}>0 \mid \mathcal{F}_{t}\right)$

Under the $\mathrm{V}$-measure, the dynamics of $L_{f}(t, T)$ is given by:

$$
\frac{\mathrm{d} L_{f}(t, T)}{L_{f}(t, T)}=\left(\left(\rho_{f D}^{f L} * \sigma_{d D}-\rho_{x x}^{f L} * \sigma_{X}\right) * \gamma_{f L}+\gamma_{f L}^{2}\right) * \mathrm{~d} t+\gamma_{f L} * \mathrm{~d} W_{f L}^{V}(t)
$$

Solving this using Itô formula, we get:

$$
\begin{aligned}
L_{f}(T, T) & =L_{f}(t, T) \mathrm{e}^{\left(\left(\rho_{f D}^{f L} * \sigma_{d D}-\rho_{x x}^{f L} * \sigma_{X}\right) * \gamma_{f L}+\frac{1}{2} * \gamma_{f L}^{2}\right)(T-t)+\gamma_{f L}\left(W_{f L}^{V}(T)-W_{f L}^{V}(t)\right)} \\
& =L_{f}(t, T) \mathrm{e}^{R}
\end{aligned}
$$

where

$$
\begin{gathered}
R=\left(\left(\rho_{f D}^{f L} * \sigma_{d D}-\rho_{x x}^{f L} * \sigma_{X}\right) * \gamma_{f L}+\frac{1}{2} * \gamma_{f L}^{2}\right)(T-t)+\gamma_{f L}\left(W_{f L}^{V}(T)-W_{f L}^{V}\right)(t) \\
\mathbb{E}[R]=\mu_{R}=\left(\left(\rho_{f D}^{f L} * \sigma_{d D}-\rho_{x x}^{f L} * \sigma_{X}\right) * \gamma_{f L}+\frac{1}{2} * \gamma_{f L}^{2}\right)(T-t) \\
\mathbb{V}(R)=\sigma_{R}^{2}=\gamma_{f L}^{2} *(T-t)
\end{gathered}
$$

such that $R \sim N\left(\mu_{R}, \sigma_{R}^{2}\right)$. Therefore:

$$
\begin{aligned}
& \operatorname{Pr}^{\mathbb{V}}\left(L_{f}(T, T)-K_{f}>0 \mid \mathcal{F}_{t}\right) \\
& =\operatorname{Pr}\left(L_{f}(t, T) \mathrm{e}^{R}-K_{f}>0 \mid \mathcal{F}_{t}\right)=\operatorname{Pr}\left(\mathrm{e}^{R}>\frac{K_{f}}{L_{f}(t, T)} \mid \mathcal{F}_{t}\right) \\
& =\operatorname{Pr}\left(R>\ln \left(\frac{K_{f}}{L_{f}(t, T)}\right) \mid \mathcal{F}_{t}\right)=\int_{L^{*}}^{\infty} \frac{1}{\sigma_{R} \sqrt{2 \pi}} \mathrm{e}^{-\frac{1}{2}\left(\frac{R-\mu_{R}}{\sigma_{R}}\right)^{2}} \mathrm{~d} R \\
& =\int_{Z_{1}^{*}}^{\infty} \frac{1}{\sqrt{2 \pi}} \mathrm{e}^{-\frac{1}{2} Z_{1}^{2}} \mathrm{~d} Z_{1}=\underbrace{\int_{-\infty}^{d_{1}} \frac{1}{\sqrt{2 \pi}} \mathrm{e}^{-\frac{1}{2} Z_{1}^{2}} \mathrm{~d} Z_{1}}_{\Phi\left(d_{1}\right)}
\end{aligned}
$$

where

$$
\begin{gathered}
L^{*}=\ln \left(\frac{K_{f}}{L_{f}(t, T)}\right) \\
Z_{1}=\frac{R-\mu_{R}}{\sigma_{R}} Z_{1}^{*}=\frac{1}{\sigma_{R}}\left(\ln \left(\frac{K_{f}}{L_{f}(t, T)}\right)-\mu_{R}\right)
\end{gathered}
$$




$$
d_{1}=-Z_{1}^{*}=\frac{1}{\sigma_{R}}\left(\mu_{R}+\ln \left(\frac{L_{f}(t, T)}{K_{f}}\right)\right)
$$

Hence $M$ becomes:

$$
M=L_{f}(t, T) \mathrm{e}^{\left(\rho_{f D}^{f L} * \sigma_{d D}-\rho_{x x}^{f L} * \sigma_{X}\right) * \gamma / L^{*} *(T-t)} \Phi\left(d_{1}\right)
$$

where

$$
d_{1}=\frac{\ln \left(\frac{L_{f}(t, T)}{K_{f}}\right)+\left(\left(\rho_{f D}^{f L} * \sigma_{d D}-\rho_{x x}^{f L} * \sigma_{X}\right) * \gamma_{f L}+\frac{1}{2} * \gamma_{f L}^{2}\right)(T-t)}{\gamma_{f L} * \sqrt{T-t}}
$$

\section{Solving for $\mathrm{N}$ :}

$$
\begin{aligned}
N= & \mathbb{E}^{\mathbb{Q}^{D}}\left[K_{f} I_{A} \mid \mathcal{F}_{t}\right] \\
= & K_{f} * \mathbb{E}^{\mathbb{Q}^{D}}\left[I_{A} \mid \mathcal{F}_{t}\right] \\
= & K_{f} * 0 * \operatorname{Pr}^{\mathbb{Q}^{D}}\left[L_{f}(T, T)-K_{f} \leq 0 \mid \mathcal{F}_{t}\right] \\
& +K_{f} * 1 * \operatorname{Pr}^{\mathbb{Q}^{D}}\left[L_{f}(T, T)-K_{f} \leq 0 \mid \mathcal{F}_{t}\right] \\
= & K_{f} * \operatorname{Pr}^{\mathbb{Q}^{D}}\left[L_{f}[T, T]-K_{f} \leq 0 \mid \mathcal{F}_{t}\right]
\end{aligned}
$$

Solving for $\operatorname{Pr}^{\mathbb{Q}^{D}}\left[L_{f}(T, T)-K_{f} \leq 0 \mid \mathcal{F}_{t}\right]$

We saw that under the $\mathbb{Q}^{D}$-measure,

$$
\begin{aligned}
& L_{f}(T, T)=L_{f}(t, T) \mathrm{e}^{\left(\left(\rho_{f D}^{f H} * \sigma_{d D}-\rho_{x x}^{f} * \sigma_{X}\right) * \gamma_{f L}-\frac{1}{2} * \gamma_{J L}^{2}\right)(T-t)+\gamma_{f L}\left(W_{f L}(T)-W_{f L}(t)\right)} \\
& =L_{f}(t, T) \mathrm{e}^{S}
\end{aligned}
$$

where

$$
\begin{gathered}
S=\left(\left(\rho_{f D}^{f L} * \sigma_{d D}-\rho_{x x}^{f L} * \sigma_{X}\right) * \gamma_{f L}-\frac{1}{2} * \gamma_{f L}^{2}\right)(T-t)+\gamma_{f L}\left(W_{f L}(T)-W_{f L}(t)\right) \\
\mathbb{E}[S]=\mu_{S}=\left(\left(\rho_{f D}^{f L} * \sigma_{d D}-\rho_{x x}^{f L} * \sigma_{X}\right) * \gamma_{f L}-\frac{1}{2} * \gamma_{f L}^{2}\right)(T-t) \\
\mathbb{V}(S)=\sigma_{S}^{2}=\gamma_{f L}^{2} *(T-t)
\end{gathered}
$$

such that $S \sim N\left(\mu_{S}, \sigma_{S}^{2}\right)$. Therefore:

$$
\begin{aligned}
& \operatorname{Pr}^{\mathbb{Q}^{D}}\left(L_{f}(T, T)-K_{f}>0 \mid \mathcal{F}_{t}\right) \\
& =\operatorname{Pr}\left(L_{f}(t, T) \mathrm{e}^{S}-K_{f}>0\right)=\operatorname{Pr}\left(\mathrm{e}^{S}>\left(\frac{K_{f}}{L_{f}(t, T)}\right)\right) \\
& =\operatorname{Pr}\left(S>\ln \left(\frac{K_{f}}{L_{f}(t, T)}\right)\right)=\int_{L^{*}}^{\infty} \frac{1}{\sigma_{S} \sqrt{2 \pi}} \mathrm{e}^{-\frac{1}{2}\left(\frac{S-\mu_{S}}{\sigma_{S}}\right)^{2}} \mathrm{~d} S \\
& =\int_{Z_{2}^{*}}^{\infty} \frac{1}{\sqrt{2 \pi}} \mathrm{e}^{-\frac{1}{2} Z_{2}^{2}} \mathrm{~d} Z_{2}=\underbrace{\int_{-\infty}^{d_{2}} \frac{1}{\sqrt{2 \pi}} \mathrm{e}^{-\frac{1}{2} Z_{2}^{2}} \mathrm{~d} Z_{2}}_{\Phi\left(d_{2}\right)}
\end{aligned}
$$

where 


$$
\begin{gathered}
L^{*}=\ln \left(\frac{K_{f}}{L_{f}(t, T)}\right) ; Z_{2}=\frac{S-\mu_{S}}{\sigma_{S}} \\
Z_{2}^{*}=\frac{1}{\sigma_{S}}\left(\ln \left(\frac{K_{f}}{L_{f}(t, T)}\right)-\mu_{S}\right) \\
d_{2}=-Z_{2}^{*}=\frac{1}{\sigma_{S}}\left(\mu_{S}+\ln \left(\frac{L_{f}(t, T)}{K_{f}}\right)\right)
\end{gathered}
$$

Hence N becomes:

$$
N=K_{f} * \Phi\left(d_{2}\right)
$$

where

$$
\begin{aligned}
d_{2}= & \frac{\ln \left(\frac{L_{f}(t, T)}{K_{f}}\right)+\left(\left(\rho_{f D}^{f L} * \sigma_{d D}-\rho_{x x}^{f L} * \sigma_{X}\right) * \gamma_{f L}-\frac{1}{2} * \gamma_{f L}^{2}\right)(T-t)}{\gamma_{f L} * \sqrt{T-t}} \\
= & d_{1}-\gamma_{f L} * \sqrt{T-t}
\end{aligned}
$$

Hence, the quanto caplet price at time $t$, with payments given at maturity in domestic currency whenever the foreign risky LIBOR exceeds the foreign strike price, $K_{f}$ is given by:

$$
\begin{aligned}
& \operatorname{QCplt}\left(t, T, K_{f}, X^{0}, N_{f}\right) \\
& =\tau N_{f} X^{0} P_{d}^{D}(t, T) *\left[L_{f}(t, T) \mathrm{e}^{\left(\rho_{f D}^{f L} * \sigma_{d D}-\rho_{x x}^{f L} * \sigma_{X}\right) * \gamma_{f L} *(T-t)} \Phi\left(d_{1}\right)-K_{f} * \Phi\left(d_{2}\right)\right]
\end{aligned}
$$

where $d_{1}$ and $d_{2}$ is as expressed in Equations (47) and (54) respectively.

Remark: The Black MCCCLMM quanto floor let formula can be derived in the same way.

\section{B. ATM CAP Market Price Data}

Cap prices struck on 2/1/2018 on the 6 month USD and GBP LIBORs with maturities ranging from 1 year to 4 years were used to calibrate some of the MCCCLMM parameters to market. The USD and GBP cap price datasets provided by [36] were as summarised in Table B1 and Table B2 below.

Table B1. Actual GBP ATM CAP prices struck on 2/1/2018.

\begin{tabular}{cccc}
\hline Maturity Date & Strike Price (\%) & Lognormal Volatility (\%) & Cap Price $(\mathfrak{E})$ in bp \\
\hline $2 / 1 / 2019$ & 0.662 & 39.28 & 11.8 \\
$2 / 1 / 2020$ & 0.800 & 41.61 & 50.3 \\
$4 / 1 / 2021$ & 0.903 & 46.89 & 118.9 \\
$3 / 1 / 2022$ & 0.982 & 51.84 & 216.2 \\
$2 / 1 / 2023$ & 1.052 & 51.84 & 341.2 \\
$2 / 1 / 2024$ & 1.111 & 57.90 & 485.5 \\
$2 / 1 / 2025$ & 1.164 & 59.43 & 647.5 \\
$2 / 1 / 2026$ & 1.214 & 60.18 & 822.4 \\
$4 / 1 / 2027$ & 1.261 & 60.18 & 1006.0 \\
$3 / 1 / 2028$ & 1.305 & 59.76 & 1195.4 \\
\hline
\end{tabular}


Table B2. Actual USD ATM CAP prices struck on 2/1/2018.

\begin{tabular}{cccc}
\hline Maturity Date & Strike Price (\%) & Lognormal Volatility (\%) & Cap Price (\$) in bp \\
\hline $2 / 1 / 2019$ & 1.961 & 15.38 & 14.4 \\
$2 / 1 / 2020$ & 2.126 & 18.81 & 60.3 \\
$4 / 1 / 2021$ & 2.199 & 21.73 & 128.5 \\
$3 / 1 / 2022$ & 2.242 & 23.92 & 218.5 \\
$2 / 1 / 2023$ & 2.273 & 25.63 & 325.3 \\
$2 / 1 / 2024$ & 2.303 & 26.59 & 442.8 \\
$2 / 1 / 2025$ & 2.334 & 27.14 & 571.4 \\
$2 / 1 / 2026$ & 2.365 & 27.55 & 706.5 \\
$4 / 1 / 2027$ & 2.394 & 27.75 & 847.0 \\
$3 / 1 / 2028$ & 2.420 & 27.86 & 992.4 \\
\hline
\end{tabular}

\section{Data Availability}

The historical datasets used are freely available on the websites [11], [12], [33]. [34], [35] as at the date last accessed. The USD and GBP ATM market cap prices used (provided by [36]) are given in Appendix B. 